\title{
ARTICLE
}

Chronic myelogenous leukemia

\section{Bosutinib for pretreated patients with chronic phase chronic myeloid leukemia: primary results of the phase 4 BYOND study}

\author{
Andreas Hochhaus ${ }^{1}$. Carlo Gambacorti-Passerini ${ }^{2}$ - Camille Abboud ${ }^{3}$ - Bjørn Tore Gjertsen ${ }^{4} \cdot$ Tim H. Bümmendorf $^{5}$. \\ B. Douglas Smith ${ }^{6} \cdot$ Thomas Ernst $^{1} \cdot$ Pilar Giraldo-Castellano $^{7} \cdot$ Ulla Olsson-Strömberg ${ }^{8} \cdot$ Susanne Saussele $^{9}$. \\ Nathalie Bardy-Bouxin ${ }^{10}$. Andrea Viqueira ${ }^{11}$ - Eric Leip ${ }^{12} \cdot$ T. Alexander Russell-Smith ${ }^{13}$. Jocelyn Leone ${ }^{12}$. \\ Gianantonio Rosti ${ }^{14} \cdot$ Justin Watts ${ }^{15} \cdot$ Francis J. Giles $^{16} \cdot$ on behalf of the BYOND Study Investigators
}

Received: 25 May 2020 / Revised: 1 June 2020 / Accepted: 4 June 2020 / Published online: 22 June 2020

(c) The Author(s) 2020. This article is published with open access

\begin{abstract}
Bosutinib is approved for newly diagnosed Philadelphia chromosome-positive $(\mathrm{Ph}+)$ chronic phase $(\mathrm{CP})$ chronic myeloid leukemia (CML) and for $\mathrm{Ph}+\mathrm{CP}$, accelerated (AP), or blast (BP) phase CML after prior treatment with tyrosine kinase inhibitors (TKIs). In the ongoing phase 4 BYOND study (NCT02228382), 163 CML patients resistant/intolerant to prior TKIs $(n=156 \mathrm{Ph}+\mathrm{CP}$ CML, $n=4 \mathrm{Ph}+\mathrm{AP}$ CML, $n=3 \mathrm{Ph}$-negative $/ B C R-A B L 1+\mathrm{CML})$ received bosutinib $500 \mathrm{mg}$ once daily (starting dose). As of $\geq 1$ year after last enrolled patient (median treatment duration 23.7 months), $56.4 \%$ of $\mathrm{Ph}+\mathrm{CP}$ CML patients remained on bosutinib. Primary endpoint of cumulative confirmed major cytogenetic response (MCyR) rate by 1 year was $75.8 \%$ in $\mathrm{Ph}+\mathrm{CP}$ CML patients after one or two prior TKIs and $62.2 \%$ after three prior TKIs. Cumulative complete cytogenetic response (CCyR) and major molecular response (MMR) rates by 1 year were $80.6 \%$ and $70.5 \%$, respectively, in $\mathrm{Ph}+\mathrm{CP}$ CML patients overall. No patient progressed to AP/BP on treatment. Across all patients, the most common treatment-emergent adverse events were diarrhea (87.7\%), nausea (39.9\%), and vomiting (32.5\%). The majority of patients had confirmed MCyR by 1 year and MMR by 1 year, further supporting bosutinib use for Ph+ CP CML patients resistant/intolerant to prior TKIs.
\end{abstract}

Additional BYOND Study Investigators are listed below Acknowledgements.

Supplementary information The online version of this article (https:// doi.org/10.1038/s41375-020-0915-9) contains supplementary material, which is available to authorized users.

Andreas Hochhaus

andreas.hochhaus@med.uni-jena.de

Klinik für Innere Medizin II, Universitätsklinikum Jena, Jena, Germany

2 University of Milano-Bicocca, Monza, Italy

3 Washington University School of Medicine, St. Louis, MO, USA

4 Haukeland University Hospital, Helse Bergen, and University of Bergen, Bergen, Norway

5 Universitätsklinikum RWTH Aachen, Aachen, Germany

6 Johns Hopkins Sidney Kimmel Comprehensive Cancer Center, Baltimore, MD, USA

7 CIBER Enfermedades Raras, Miguel Servet University Hospital, Zaragoza, Spain

\section{Introduction}

Chronic myeloid leukemia (CML) is a myeloproliferative neoplasm characterized by the presence of the Philadelphia chromosome $(\mathrm{Ph})$ [1]. Imatinib was the first BCR-ABL1targeting tyrosine kinase inhibitor (TKI) approved for the

8 University of Uppsala and Department of Hematology, University Hospital, Uppsala, Sweden

9 Universitätsmedizin Mannheim, Heidelberg University, Mannheim, Germany

10 Pfizer International Operation-Oncology, Paris, France

11 Pfizer SLU, Madrid, Spain

12 Pfizer Inc, Cambridge, MA, USA

13 Pfizer Inc, New York, NY, USA

14 University Hospital, University of Bologna, Bologna, Italy

15 University of Miami, Sylvester Comprehensive Cancer Center, Miami, FL, USA

16 Developmental Therapeutics Consortium, Chicago, IL, USA 
treatment of CML $[2,3]$. The 2nd-generation TKIs dasatinib, nilotinib, and bosutinib can be used as first-line therapy alternatives to imatinib for chronic phase (CP) CML [4-6]. However, patients may become resistant or intolerant to first-line TKI treatment [7-10]. Therapy options in the second-line setting are dasatinib, nilotinib, and bosutinib, or the 3rd-generation BCR-ABL1 TKI ponatinib [11-14]. TKIs radotinib and asciminib are emerging as treatment options $[9,15]$.

Approval of bosutinib for patients with $\mathrm{Ph}+\mathrm{CP}$, accelerated phase (AP), or blast phase (BP) CML previously treated with $\geq 1$ TKI was based on results from a phase $1 / 2$ study $[13,16]$. In patients with imatinib-resistant or imatinib-intolerant $\mathrm{Ph}+\mathrm{CML}$, and in patients who had received prior imatinib plus dasatinib and/or nilotinib, bosutinib $500 \mathrm{mg}$ once daily (QD) demonstrated durable efficacy and manageable toxicity after longer follow-up [17-19]. At year 5, 40\% of patients resistant/intolerant to imatinib remained on bosutinib; cumulative major cytogenetic response (MCyR), complete cytogenetic response (CCyR), and major molecular response (MMR) rates were $60 \%, 50 \%$, and $42 \%$, respectively [19]. In a 4-year followup of patients receiving bosutinib in the third- or fourth-line setting, cumulative MCyR and CCyR rates were $40 \%$ and $32 \%$, respectively [18]. Across all patients with $\mathrm{Ph}+\mathrm{CP}$ CML in that study, the most common $(\geq 30 \%)$ adverse events (AEs) were diarrhea, nausea, and vomiting $[18,19]$.

The purpose of the current phase 4 study was to provide further information on the treatment with bosutinib of patients with CML resistant/intolerant to prior TKIs or who were otherwise not appropriate for treatment with other TKIs. This study also aimed to fulfill a post-authorization commitment to the European Medicines Agency regarding the efficacy and safety of bosutinib in this patient population.

\section{Methods}

\section{Study design and patients}

BYOND (NCT02228382) is an ongoing, single-arm, openlabel, non-randomized phase 4 study of bosutinib in patients with chronic or advanced $\mathrm{Ph}+\mathrm{CML}$ who have failed prior treatment with TKIs. Eligible patients were adults with a cytogenetic or qualitative polymerase chain reaction-based diagnosis of $\mathrm{Ph}+$ and/or $B C R-A B L 1+\mathrm{CML}$ (from initial diagnosis), prior treatment with $\geq 1$ TKI for CML and adequate hepatic/renal function. Any CML phase was permitted, as long as the patient was resistant/intolerant to prior TKIs. Patients with CP CML and treated with one or two prior TKIs were required to have Eastern Cooperative Oncology Group performance status (ECOG PS) 0 or 1; those with CP CML after three prior TKIs and with AP/BP CML could have ECOG PS 0-3. Patients with leptomeningeal leukemia or a known BCR-ABL1 T315I or V299L mutation were excluded. Additional details on eligibility criteria are in Supplementary Methods.

Patients received bosutinib at a starting dose of $500 \mathrm{mg}$ QD. Dose escalation to a maximum of $600 \mathrm{mg}$ QD was permitted due to unsatisfactory response or signs of disease progression in the absence of any grade $3 / 4$ or persistent grade 2 AEs. Dose reduction to 400, 300, or $200 \mathrm{mg}$ QD due to toxicity/tolerability was permitted (see Supplementary Methods). Patients were to receive bosutinib for up to 4 years from the time of first dose, unless disease progression, unacceptable toxicity, withdrawal of consent, death, or study discontinuation. Patients who discontinued bosutinib prior to completing 4 years of therapy were to be followed for survival until they completed 4 years on study.

The study was approved by institutional review boards and independent ethics committees at each center. The study was conducted in accordance with all local legal and regulatory requirements, as well as the general principles set forth in the International Ethical Guidelines for Biomedical Research Involving Human Patients, Guidelines for Good Clinical Practice and the Declaration of Helsinki. All patients provided written informed consent.

\section{Endpoints and analyses}

The primary endpoints were cumulative confirmed MCyR (in two consecutive analyses $\geq 28$ days apart) by 1 year (52 weeks) in patients with $\mathrm{Ph}+\mathrm{CP}$ CML treated with one or two prior TKIs and three prior TKIs, and cumulative confirmed overall hematologic response (OHR; in two consecutive analyses $\geq 28$ days apart) by 1 year ( 52 weeks) in patients with AP or BP CML. Cumulative confirmed MCyR was defined as CCyR $(0 \% \mathrm{Ph}+$ from $\geq 20$ metaphases or $<1 \%$ fluorescent in situ hybridization [FISH] positive cells from $\geq 200$ interphase nuclei) or partial cytogenetic response (PCyR; $>0 \%, \leq 35 \% \mathrm{Ph}+$ ). To be considered a responder, the patient must have had maintenance of baseline response for $\geq 52$ weeks for cytogenetic response or an improvement from baseline. Patients with PCyR at baseline must have attained CCyR on-treatment to be considered a cytogenetic responder. Patients with at least MMR and a deeper molecular response (MR) than baseline were counted as confirmed CCyR. Cumulative confirmed OHR was defined as complete hematologic response (CHR) or return to $\mathrm{CP}$.

Key secondary and exploratory endpoints included: cumulative MCyR (unconfirmed); cumulative MMR (BCR$A B L 1$ International Scale [IS] $\leq 0.1 \%), \mathrm{MR}^{4}(B C R-A B L 1$ IS $\leq 0.01 \%)$, and $\mathrm{MR}^{4.5}$ (BCR-ABL1 IS $\left.\leq 0.0032 \%\right) ; B C R$ $A B L 1$ mutational analyses; on-treatment transformation to 
AP or BP CML; overall survival (OS); safety; and patientreported outcome (PRO) measures.

Analyses for molecular, cytogenetic, and hematologic responses are described in Supplementary Methods. CCyR was imputed from MMR on a specific date if there was no valid cytogenetic assessment. Time to response was defined as the interval from the date of first dose of bosutinib to initial response. Non-responders were censored at the last valid assessment date for the respective endpoint. OS was defined as the interval from the date of first dose of bosutinib to the date of death due to any cause. Patients not known to have died were censored at the last known alive date. Time to response was estimated using cumulative incidence, adjusting for the competing risk of treatment discontinuation without the event; OS was estimated using the Kaplan-Meier method. Two-sided $95 \%$ confidence interval (CI) for response rate was determined using the exact binomial method. For Kaplan-Meier's yearly probability estimates, two-sided 95\% CI was based on Greenwood's formula using a $\log (-\log )$ transformation.

Treatment-emergent AEs (TEAEs), serious AEs, and laboratory evaluations were assessed up to 28 days after last dose. Events were graded according to the National Cancer Institute Common Terminology Criteria for Adverse Events, v4.0. The frequency of selected adverse events of special interest was analyzed by selecting Medical Dictionary for Regulatory Activities (MedDRA) system organ class higher level group, higher level and preferred terms and standardized MedDRA queries to generate TEAE clusters (see Supplementary Methods).

PROs were assessed using the Functional Assessment of Cancer Therapy-Leukemia (FACT-Leu) quality-of-life (QoL) questionnaire (see Supplementary Methods). For each cohort at each of the timepoints, summary statistics for the observed values as well as changes from baseline were estimated. As a supplemental post hoc analysis, a repeated measures longitudinal model was used to estimate the relationship between MR (screening to month 12 represented by a log-reduction scale) as a predictor and FACTLeu total score and each domain score as an outcome. The standardized effect sizes were calculated to determine strength of effects and allow comparisons across FACT-Leu domains.

This study did not include any formal sample size determination and results are descriptive only. Approximately 150 patients with $\mathrm{Ph}+\mathrm{CML}$ were to be enrolled, including $\geq 45$ patients with $\mathrm{CP}, \mathrm{AP}$, or BP CML treated in the fourth-line or later setting. All treated patients with $\mathrm{Ph}+$ CML with a valid baseline efficacy assessment for the respective endpoint (evaluable population) were included in the molecular, cytogenetic, and hematologic efficacy analyses. All patients who received $\geq 1$ dose of study drug (full analysis set) were included in the safety analyses and those with $\mathrm{Ph}+\mathrm{CP}$ CML were included in the PRO analyses. $\mathrm{Ph}+\mathrm{CP}$ CML patients were also analyzed by resistance or intolerance to prior TKIs as assessed by the investigator (Supplementary Methods). Data are from an unlocked trial database with a cut-off date of September 18, 2018, $\geq 12$ months after last enrolled patient.

\section{Results}

\section{Patients and treatment}

A total of 163 patients were enrolled between November 20, 2014 and September 18, 2017 across 41 study centers in eight countries. Of 163 patients who received bosutinib, 156 had $\mathrm{Ph}+\mathrm{CP}$ CML, four had $\mathrm{Ph}+\mathrm{AP}$ CML, and three had $\mathrm{Ph}-/ B C R-A B L 1+\mathrm{CP}$ CML. Across Ph+ CP CML cohorts, $51.9 \%$ of patients were male and median age was 61.0 years; $29.5 \%, 39.1 \%$, and $31.4 \%$ received bosutinib as second-, third- and fourth-line TKI therapy, respectively (Table 1). In all, 53.2\% of patients with $\mathrm{Ph}+\mathrm{CP}$ CML were resistant to $\geq 1$ prior TKI and $46.8 \%$ were intolerant to all prior TKIs. Imatinib was the most common prior TKI, received by $90.4 \%$ of patients. All patients with AP CML were male, with a median age of 40.0 years; two each received bosutinib as third- and fourth-line TKI therapy. All patients with $\mathrm{Ph}-\mathrm{CML}$ were male, with a median age of 63.0 years; two received bosutinib as second-line and one as third-line TKI therapy.

As of $\geq 1$ year after last enrolled patient $(\sim 85 \%$ with $\geq 2$ year follow-up), $56.4 \%$ of patients with $\mathrm{Ph}+\mathrm{CP} \mathrm{CML}$ remained on bosutinib: $67.4 \%, 54.1 \%$, and $49.0 \%$ in the second-, third-, and fourth-line cohorts, respectively (Fig. 1). In all, $59.0 \%$ of TKI-resistant patients and $53.4 \%$ of TKI-intolerant patients remained on bosutinib. The most common primary reasons for permanent treatment discontinuation were AEs in $39(25.0 \%)$ and insufficient clinical response in eight $(5.1 \%)$ patients. Three of four patients with AP CML discontinued bosutinib due to AE, insufficient response, or lost to follow-up ( $n=1$ each). All three patients with $\mathrm{Ph}-\mathrm{CP} \mathrm{CML}$ discontinued bosutinib due to $\mathrm{AE}(n=2)$ or death $(n=1)$.

Median (range) duration of bosutinib treatment was 23.7 (0.2-42.2) months in the $\mathrm{Ph}+\mathrm{CP}$ CML cohort: 25.9 (0.9-41.2), $24.2(0.4-42.2)$, and $12.3(0.2-41.9)$ in the second-, third-, and fourth-line cohorts, respectively. In the $\mathrm{AP}$ and $\mathrm{Ph}-\mathrm{CML}$ cohorts, median (range) duration of bosutinib treatment was 18.0 (1.6-32.3) and 7.2 (3.4-25.8) months, respectively. Median (range) dose intensity in the $\mathrm{Ph}+$ CP CML cohort was 313.1 (79.7-560.6) mg/day: 320.1 (98.4-560.6), 309.4 (79.7-500.0), and 308.0 (125.0-500.0) in the second-, third-, and fourth-line cohorts, respectively. In the $\mathrm{AP}$ and $\mathrm{Ph}-\mathrm{CML}$ cohorts, median 
Table 1 Demographic and baseline characteristics across patients with $\mathrm{Ph}+\mathrm{CP} \mathrm{CML}$.

\begin{tabular}{|c|c|c|c|c|}
\hline \multirow[t]{2}{*}{ Characteristic } & \multicolumn{3}{|l|}{ Line of treatment } & \multirow[t]{2}{*}{ Total $(N=156)$} \\
\hline & $\begin{array}{l}\text { Second-line } \\
(n=46)\end{array}$ & $\begin{array}{l}\text { Third-line } \\
(n=61)\end{array}$ & $\begin{array}{l}\text { Fourth-line } \\
(n=49)\end{array}$ & \\
\hline Male, $n(\%)$ & $23(50.0)$ & $37(60.7)$ & $21(42.9)$ & $81(51.9)$ \\
\hline Age, median (range), years & $54.0(19.0-88.0)$ & $65.0(27.0-85.0)$ & $61.0(21.0-85.0)$ & $61.0(19.0-88.0)$ \\
\hline \multicolumn{5}{|l|}{ Age group, $n(\%)$} \\
\hline$<65$ years & $34(73.9)$ & $30(49.2)$ & $32(65.3)$ & $96(61.5)$ \\
\hline$\geq 65$ years & $12(26.1)$ & $31(50.8)$ & $17(34.7)$ & $60(38.5)$ \\
\hline \multicolumn{5}{|l|}{ ECOG PS, $n(\%)$} \\
\hline 0 & $34(73.9)$ & $40(65.6)$ & $32(65.3)$ & $106(67.9)$ \\
\hline 1 & $12(26.1)$ & $20(32.8)$ & $13(26.5)$ & $45(28.8)$ \\
\hline 2 & 0 & $1(1.6)$ & $4(8.2)$ & $5(3.2)$ \\
\hline $\begin{array}{l}\text { Median (range) duration since } \\
\text { CML diagnosis, years }\end{array}$ & $2.2(0.2-11.4)$ & $5.0(0.3-18.6)$ & $7.3(0.7-27.7)$ & $4.7(0.2-27.7)$ \\
\hline \multicolumn{5}{|l|}{ Prior TKI, $n(\%)^{\mathrm{a}}$} \\
\hline Imatinib & $35(76.1)$ & $57(93.4)$ & $49(100)$ & $141(90.4)$ \\
\hline Dasatinib & $5(10.9)$ & $41(67.2)$ & $49(100)$ & $95(60.9)$ \\
\hline Nilotinib & $6(13.0)$ & $24(39.3)$ & $49(100)$ & $79(50.6)$ \\
\hline Prior interferon alpha, $n(\%)$ & $2(4.3)$ & $3(4.9)$ & $6(12.2)$ & $11(7.1)$ \\
\hline Resistant to any prior TKI, $n(\%)$ & $17(37.0)$ & $35(57.4)$ & $31(63.3)$ & $83(53.2)$ \\
\hline Intolerant to all prior TKIs, $n(\%)$ & $29(63.0)$ & $26(42.6)$ & $18(36.7)$ & $73(46.8)$ \\
\hline
\end{tabular}

Full analysis set.

$C M L$ chronic myeloid leukemia, $C P$ chronic phase, ECOG PS Eastern Cooperative Oncology Group performance status, $P h$ Philadelphia chromosome, TKI tyrosine kinase inhibitor.

${ }^{a}$ In the third-line cohort, 37 (60.7\%) of patients received prior imatinib and dasatinib, $20(32.8 \%)$ of patients received prior imatinib and nilotinib and $4(6.6 \%)$ of patients received prior dasatinib and nilotinib. (range) dose intensity was 497.9 (346.6-500.0) and 296.2 (81.0-422.8) $\mathrm{mg} /$ day, respectively. Median (range) duration of bosutinib treatment was $23.4(0.2-42.2)$ months in TKIresistant and $25.3(0.4-41.9)$ months in TKI-intolerant patients, respectively. Corresponding median (range) dose intensity was 405.9 (125.0-560.6) and 292.0 (79.7-500.0) $\mathrm{mg} /$ day. At all timepoints, $500 \mathrm{mg}$ QD was the most commonly utilized dosage and $>50 \%$ of patients with $\mathrm{Ph}+\mathrm{CP}$ CML were receiving 400 or $500 \mathrm{mg}$ QD (Supplementary Fig. S1).

\section{Efficacy}

Of 144 evaluable patients with $\mathrm{Ph}+\mathrm{CP} \mathrm{CML}$, the primary endpoint of cumulative confirmed MCyR rate $(95 \% \mathrm{CI})$ by 1 year was $75.8 \%(66.1-83.8 \%)$ in those treated with one or two prior TKIs, and $62.2 \%$ (46.5-76.2\%) in those previously treated with three TKIs. In all, $112(77.8 \%)$ patients with $\mathrm{Ph}+\mathrm{CP}$ CML had MCyR at baseline. In the overall $\mathrm{Ph}+\mathrm{CP}$ CML cohort, the cumulative confirmed MCyR rate $(95 \% \mathrm{CI})$ by 1 year was $71.5 \%(63.4-78.7 \%) ; 64.6 \%$ of patients achieved a deeper response relative to baseline and $6.9 \%$ maintained their baseline response for $\geq 1$ year. In the four patients with AP CML, the primary endpoint of cumulative confirmed OHR rate $(95 \% \mathrm{CI})$ by 1 year was $75.0 \%$ (19.4-99.4\%), as was cumulative confirmed CHR rate.

Cumulative MCyR and CCyR rates, respectively, by 1 year were 83.3 and $80.6 \%$ in patients with $\mathrm{Ph}+\mathrm{CP} \mathrm{CML}$ (TKI-resistant: 79.2 and 75.3\%; TKI-intolerant: 88.1 and 86.6\%); cumulative MCyR and CCyR rates by line of therapy are shown in Table 2. In patients without the respective baseline response, cumulative $\mathrm{MCyR}$ and $\mathrm{CCyR}$ rates, respectively, by 1 year were 59.4 and $63.5 \%$ (TKIresistant: 56.5 and 58.8\%; TKI-intolerant: 66.7 and 72.2\%; Table 2). Cytogenetic responses were achieved within 1 year with the exception of one TKI-resistant patient who achieved a CCyR after month 12 .

The cumulative MMR rate by 1 year was $70.5 \%$ in the overall $\mathrm{Ph}+\mathrm{CP}$ CML cohort (TKI-resistant: $60.5 \%$; TKIintolerant: $80.8 \%$ ); rates according to line of therapy are shown in Table 3. In patients without MMR at baseline, the cumulative MMR rate by 1 year was $58.2 \%$ (TKI-resistant: 43.8\%; TKI-intolerant: $80.6 \%$ ). (Table 3). By 1 year, cumulative $\mathrm{MR}^{4}$ and $\mathrm{MR}^{4.5}$ rates, respectively, were 51.0 and $33.6 \%$ (TKI-resistant: 39.5 and $25.0 \%$; TKI-intolerant: 63.0 and $42.5 \%$ ). In patients without the respective response 


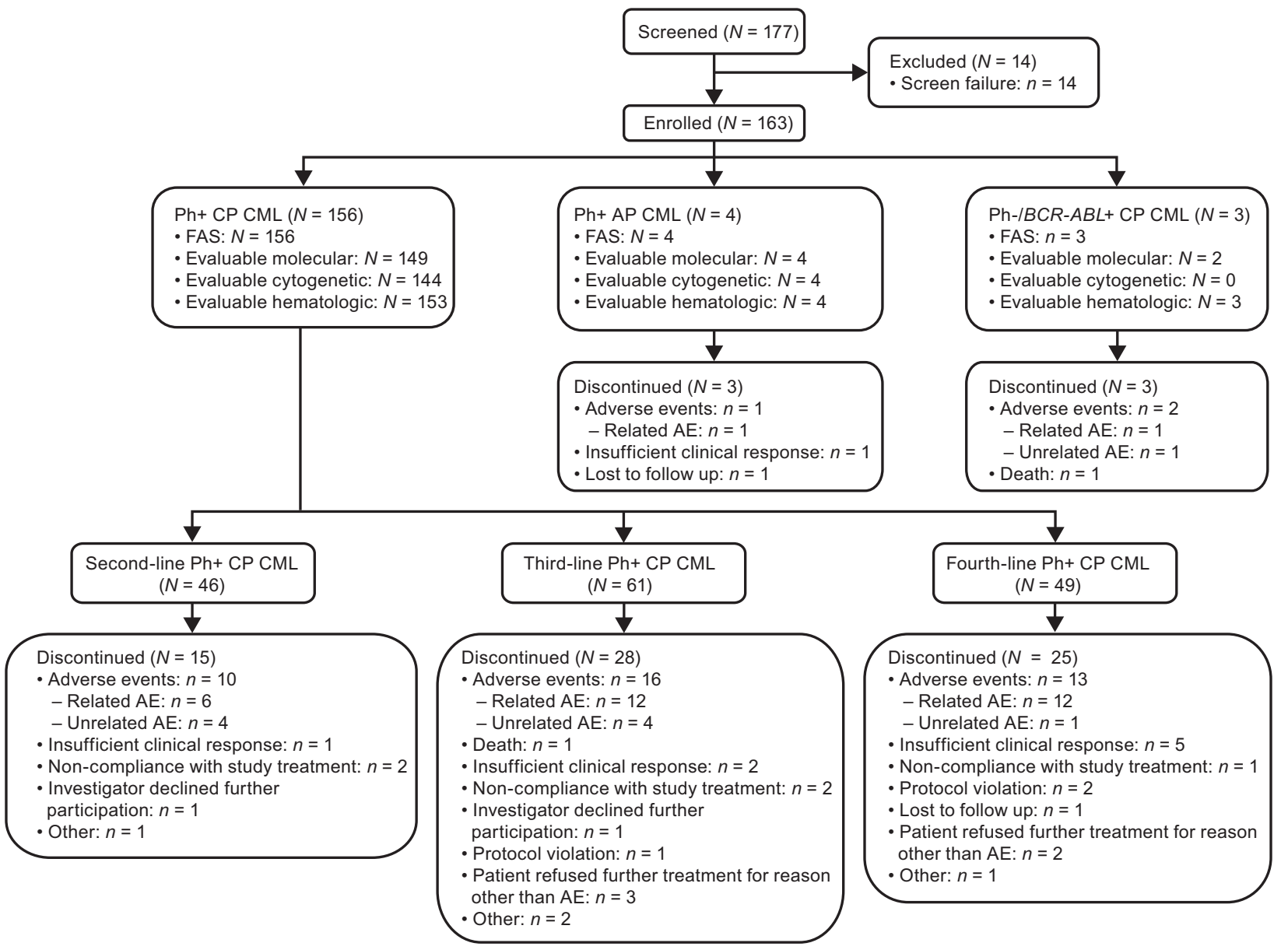

Fig. 1 Patient disposition. Full analysis set. The 14 participants screened but not enrolled did not meet the eligibility criteria. $A E$ adverse events, $A P$ accelerated phase, $C M L$ chronic myeloid leukemia, $C P$ chronic phase, $F A S$ full analysis set, $P h$ Philadelphia chromosome.

Table 2 Cumulative cytogenetic response rates by 1 year in patients with Ph + CP CML: total cohort, by line of therapy, and by TKI resistance or intolerance (overall and excluding patients with the respective baseline response).

\begin{tabular}{llllll} 
Total $N=156$ & By line of therapy & & \multicolumn{2}{l}{ By TKI resistance or intolerance } \\
\cline { 2 - 3 } \cline { 5 - 6 } & Second-line $n=46$ & Third-line $n=61$ & Fourth-line $n=49$ & Resistant $n=83 \quad$ Intolerant $n=73$
\end{tabular}

Cumulative cytogenetic response, $\%(95 \% \mathrm{CI})$

$\begin{array}{cllllll}\text { Evaluable patients, } n & 144 & 43 & 56 & 45 & 77 & 67 \\ \text { MCyR } & 83.3(76.2-89.0) & 88.4(74.9-96.1) & 83.9(71.7-92.4) & 77.8(62.9-88.8) & 79.2(68.5-87.6) & 88.1(77.8-94.7) \\ \text { CCyR } & 80.6(73.1-86.7) & 83.7(69.3-93.2) & 83.9(71.7-92.4) & 73.3(58.1-85.4) & 75.3(64.2-84.4) & 86.6(76.0-93.7) \\ \text { Cumulative cytogenetic response in patients } & \text { without the respective baseline response, \% (95\% CI) } & & \\ \text { Evaluable patients, } n & 32 & 10 & 10 & 12 & 23 & 9 \\ \text { MCyR } & 59.4(40.6-76.3) & 80.0(44.4-97.5) & 60.0(26.2-87.8) & 41.7(15.2-72.3) & 56.5(34.5-76.8) & 66.7(29.9-92.5) \\ \text { Evaluable patients, } n & 52 & 16 & 19 & 17 & 34 & 18 \\ \text { CCyR } & 63.5(49.0-76.4) & 75.0(47.6-92.7) & 68.4(43.4-87.4) & 47.1(23.0-72.2) & 58.8(40.7-75.4) & 72.2(46.5-90.3)\end{array}$

Evaluable cytogenetic population. To be considered a responder, the patient must have maintenance of baseline response while on-treatment or an improvement from baseline. Patients with MMR or better are counted as CCyR if a valid cytogenetic assessment is not available on a specific date. Associated two-sided $95 \%$ CI based on the exact method by Clopper-Pearson.

$C C y R$ complete cytogenetic response, $C I$ confidence interval, $C M L$ chronic myeloid leukemia, $C P$ chronic phase, $M C y R$ major cytogenetic response, $P h$ Philadelphia chromosome, TKI tyrosine kinase inhibitor. 
Table 3 Cumulative molecular response rates by 1 year, by 2 years, and any time on treatment in patients with Ph $+\mathrm{CP} C M L$ : total cohort, by line of therapy and by TKI resistance or intolerance (overall and excluding patients with the respective baseline response).

\begin{tabular}{|c|c|c|c|c|c|c|}
\hline & \multirow[t]{2}{*}{ Total $N=156$} & \multicolumn{3}{|l|}{ By line of therapy } & \multicolumn{2}{|c|}{ By TKI resistance or intolerance } \\
\hline & & Second-line $n=46$ & Third-line $n=61$ & Fourth-line $n=49$ & Resistant $n=83$ & Intolerant $n=73$ \\
\hline \multicolumn{7}{|c|}{ Cumulative molecular response, $\%(95 \% \mathrm{CI})$} \\
\hline Evaluable patients, $n$ & 149 & 46 & 55 & 48 & 76 & 73 \\
\hline \multicolumn{7}{|l|}{ MMR } \\
\hline By 1 year & $70.5(62.5-77.7)$ & $80.4(66.1-90.6)$ & $74.5(61.0-85.3)$ & $56.3(41.2-70.5)$ & $60.5(48.6-71.6)$ & $80.8(69.9-89.1)$ \\
\hline By 2 years & $71.1(63.2-78.3)$ & $82.6(68.6-92.2)$ & $74.5(61.0-85.3)$ & $56.3(41.2-70.5)$ & $61.8(50.0-72.8)$ & $80.8(69.9-89.1)$ \\
\hline Any time on treatment & $71.8(63.9-78.9)$ & $82.6(68.6-92.2)$ & $76.4(63.0-86.8)$ & $56.3(41.2-70.5)$ & $61.8(50.0-72.8)$ & $82.2(71.5-90.2)$ \\
\hline \multicolumn{7}{|l|}{$\mathrm{MR}^{4}$} \\
\hline By 1 year & $51.0(42.7-59.3)$ & $58.7(43.2-73.0)$ & $54.5(40.6-68.0)$ & $39.6(25.8-54.7)$ & $39.5(28.4-51.4)$ & $63.0(50.9-74.0)$ \\
\hline By 2 years & $55.7(47.3-63.8)$ & $67.4(52.0-80.5)$ & $60.0(45.9-73.0)$ & $39.6(25.8-54.7)$ & $46.1(34.5-57.9)$ & $65.8(53.7-76.5)$ \\
\hline Any time on treatment & $57.0(48.7-65.1)$ & $69.6(54.2-82.3)$ & $61.8(47.7-74.6)$ & $39.6(25.8-54.7)$ & $46.1(34.5-57.9)$ & $68.5(56.6-78.9)$ \\
\hline \multicolumn{7}{|l|}{$\mathrm{MR}^{4.5}$} \\
\hline By 1 year & $33.6(26.0-41.7)$ & $32.6(19.5-48.0)$ & $36.4(23.8-50.4)$ & $31.3(18.7-46.3)$ & $25.0(15.8-36.3)$ & $42.5(31.0-54.6)$ \\
\hline By 2 years & $43.0(34.9-51.3)$ & $47.8(32.9-63.1)$ & $45.5(32.0-59.4)$ & $35.4(22.2-50.5)$ & $35.5(24.9-47.3)$ & $50.7(38.7-62.6)$ \\
\hline Any time on treatment & $46.3(38.1-54.7)$ & $56.5(41.1-71.1)$ & $47.3(33.7-61.2)$ & $35.4(22.2-50.5)$ & $36.8(26.1-48.7)$ & $56.2(44.1-67.8)$ \\
\hline \multicolumn{7}{|c|}{ Cumulative molecular response in patients without the respective baseline response, $\%(95 \% \mathrm{CI})$} \\
\hline Evaluable patients, $n$ & 79 & 25 & 28 & 26 & 48 & 31 \\
\hline \multicolumn{7}{|l|}{ MMR } \\
\hline By 1 year & $58.2(46.6-69.2)$ & $72.0(50.6-87.9)$ & $64.3(44.1-81.4)$ & $38.5(20.2-59.4)$ & $43.8(29.5-58.8)$ & $80.6(62.5-92.5)$ \\
\hline By 2 years & $59.5(47.9-70.4)$ & $76.0(54.9-90.6)$ & $64.3(44.1-81.4)$ & $38.5(20.2-59.4)$ & $45.8(31.4-60.8)$ & $80.6(62.5-92.5)$ \\
\hline Any time on treatment & $59.5(47.9-70.4)$ & $76.0(54.9-90.6)$ & $64.3(44.1-81.4)$ & $38.5(20.2-59.4)$ & $45.8(31.4-60.8)$ & $80.6(62.5-92.5)$ \\
\hline Evaluable patients, $n$ & 112 & 37 & 38 & 37 & 60 & 52 \\
\hline \multicolumn{7}{|l|}{$\mathrm{MR}^{4}$} \\
\hline By 1 year & $42.0(32.7-51.7)$ & $51.4(34.4-68.1)$ & $44.7(28.6-61.7)$ & $29.7(15.9-47.0)$ & $26.7(16.1-39.7)$ & $59.6(45.1-73.0)$ \\
\hline By 2 years & $48.2(38.7-57.9)$ & $62.2(44.8-77.5)$ & $52.6(35.8-69.0)$ & $29.7(15.9-47.0)$ & $35.0(23.1-48.4)$ & $63.5(49.0-76.4)$ \\
\hline Any time on treatment & $49.1(39.5-58.7)$ & $64.9(47.5-79.8)$ & $52.6(35.8-69.0)$ & $29.7(15.9-47.0)$ & $35.0(23.1-48.4)$ & $65.4(50.9-78.0)$ \\
\hline Evaluable patients, $n$ & 131 & 42 & 46 & 43 & 72 & 59 \\
\hline \multicolumn{7}{|l|}{$\mathrm{MR}^{4.5}$} \\
\hline By 1 year & $26.7(19.4-35.2)$ & $26.2(13.9-42.0)$ & $28.3(16.0-43.5)$ & $25.6(13.5-41.2)$ & $20.8(12.2-32.0)$ & $33.9(22.1-47.4)$ \\
\hline By 2 years & $37.4(29.1-46.3)$ & $42.9(27.7-59.0)$ & $39.1(25.1-54.6)$ & $30.2(17.2-46.1)$ & $31.9(21.4-44.0)$ & $44.1(31.2-57.6)$ \\
\hline Any time on treatment & $40.5(32.0-49.4)$ & $52.4(36.4-68.0)$ & $39.1(25.1-54.6)$ & $30.2(17.2-46.1)$ & $33.3(22.7-45.4)$ & $49.2(35.9-62.5)$ \\
\hline
\end{tabular}

Evaluable molecular population. To be considered a responder, the patient must have maintenance of baseline response while on-treatment or an improvement from baseline. MMR: $B C R-A B L 1$ IS $\leq 0.1 \%$; $\mathrm{MR}^{4}: B C R-A B L 1$ IS $\leq 0.01 \%$; $\mathrm{MR}^{4.5}: B C R-A B L 1$ IS $\leq 0.0032 \%$. Associated two-sided 95\% CI based on the exact method by Clopper-Pearson.

$C I$ confidence interval, $C M L$ chronic myeloid leukemia, $C P$ chronic phase, $I S$ international scale, $M M R$ major molecular response, $M R$ molecular response, $P h$ Philadelphia chromosome, TKI tyrosine kinase inhibitor.

at baseline, cumulative $\mathrm{MR}^{4}$ and $\mathrm{MR}^{4.5}$ rates were 42.0 and 26.7\% (TKI-resistant: 26.7 and 20.8\%; TKI-intolerant: 59.6 and $33.9 \%$ ). At any time, respective cumulative $\mathrm{MR}^{4}$ and $\mathrm{MR}^{4.5}$ rates were $57.0 \%$ and $46.3 \%$ and $49.1 \%$ and $40.5 \%$ in patients without the respective baseline response. Cumulative $\mathrm{MR}^{4}$ and $\mathrm{MR}^{4.5}$ rates at any time across therapy lines and in TKI-resistant and TKI-intolerant patients are shown in Table 3. Responding patients typically achieved MMR within 1 year of bosutinib initiation and a deep MR within 2 years of bosutinib initiation, although a small proportion of patients achieved $\mathrm{MR}$ at later time points (Fig. 2). Of three patients with $\mathrm{Ph}-/ B C R-A B L 1+\mathrm{CML}$, one each had MMR, $B C R-A B L 1$ IS $\leq 1 \%$, and no response.

Eleven patients with $\mathrm{Ph}+\mathrm{CP}$ CML had mutations at baseline; of these, two achieved $\mathrm{MR}^{5}$, one achieved $\mathrm{MR}^{4.5}$, one achieved MMR, and four achieved CHR as best response. Molecular responses were observed in patients with F359I, Y253F, A365V, and E255V mutations (Supplementary Table S1). Of 20 patients with $\mathrm{Ph}+\mathrm{CP} \mathrm{CML}$ evaluated for new $B C R-A B L 1$ point mutations, one patient 
(a)

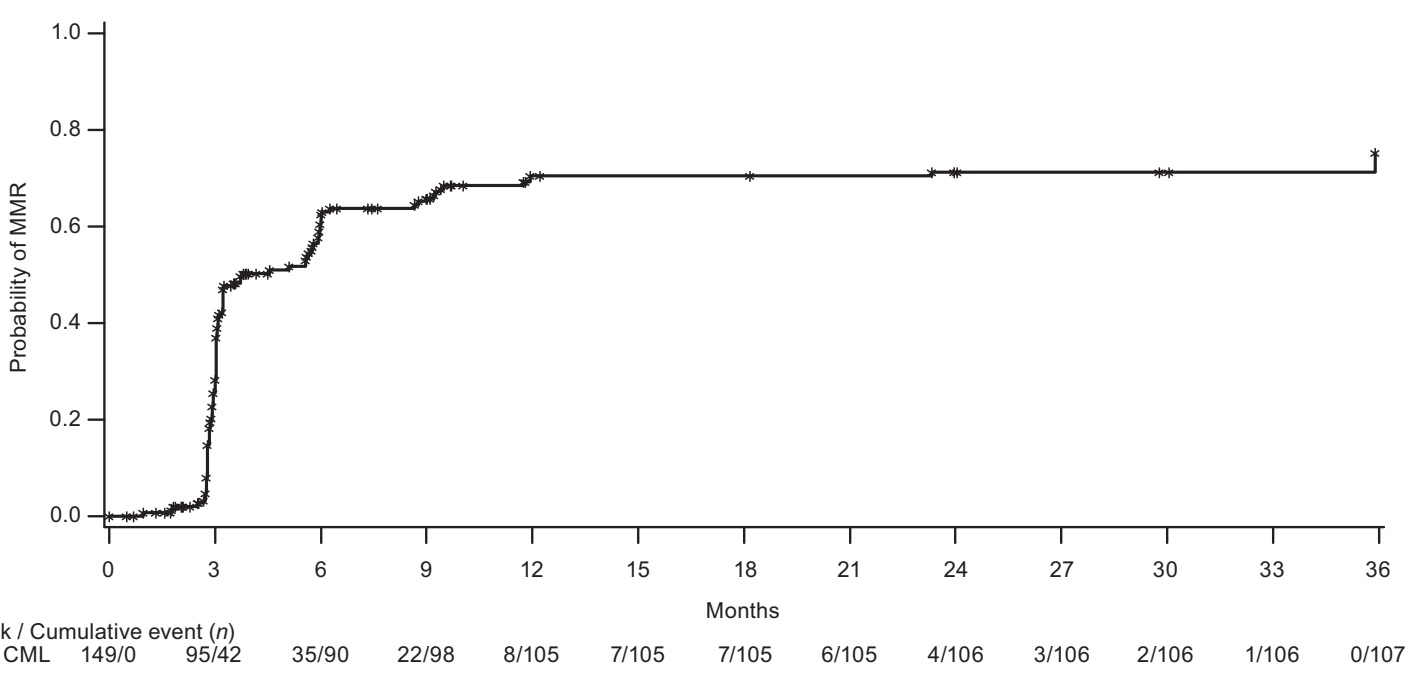

(b)

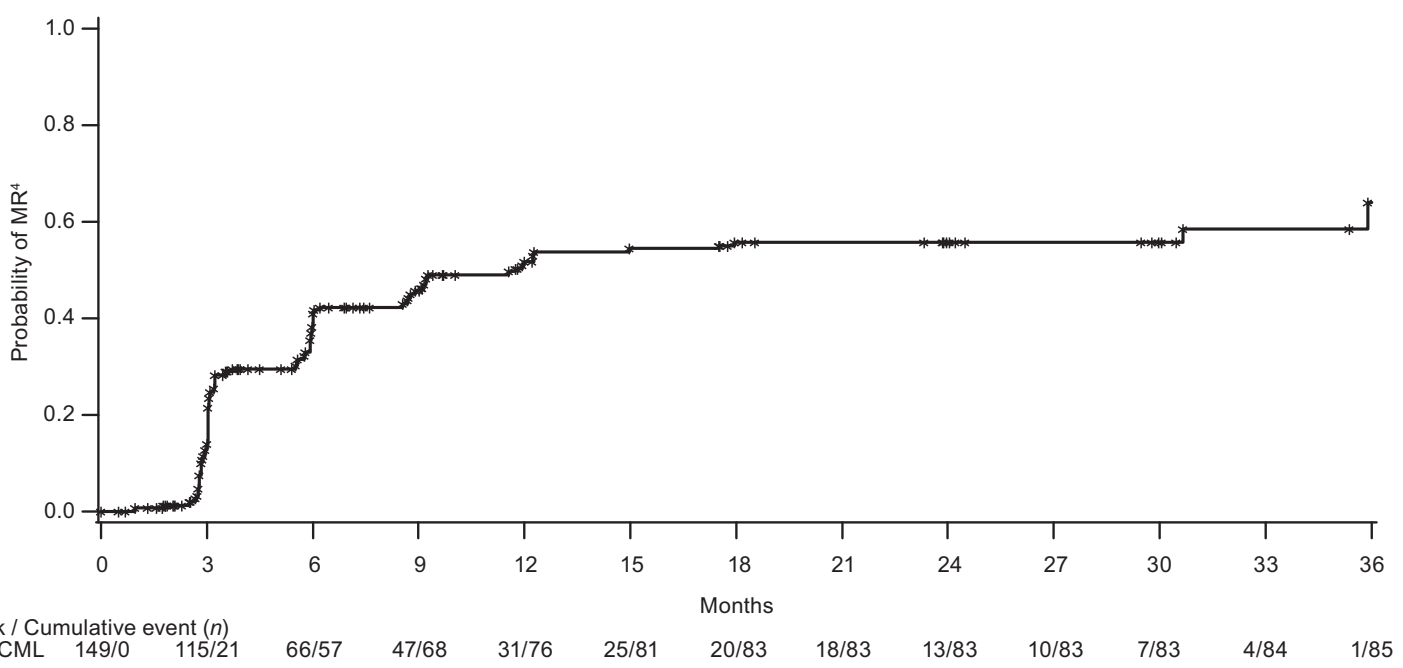

(c)

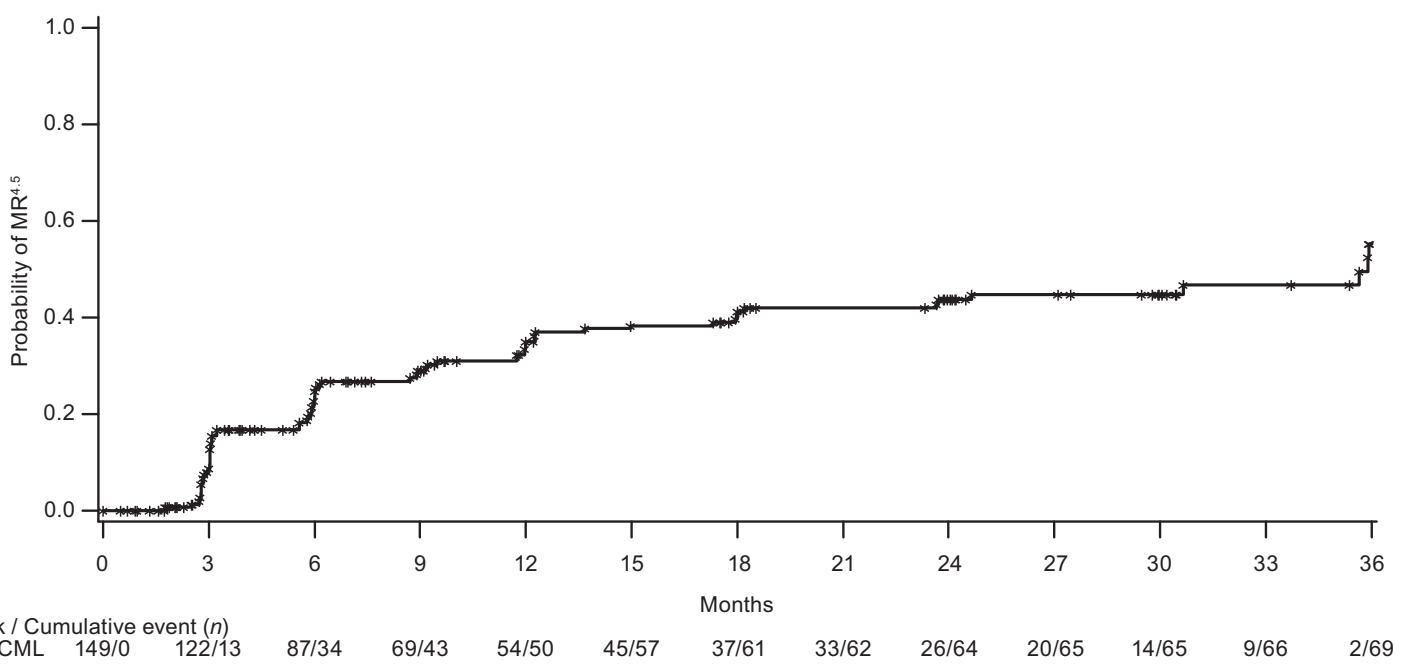

Fig. 2 Cumulative Incidence of Molecular Response in Patients with Ph+ CP CML. (a) MMR, (b) MR ${ }^{4}$, and (c) MR ${ }^{4.5}$. CML chronic myeloid leukemia, $C P$ chronic phase, $M M R$ major molecular response, $M R$ molecular response, $P h$ Philadelphia chromosome. 
in the third-line cohort with a baseline Y253F mutation had a newly detectable T315I mutation.

By the cutoff date, no patient with $\mathrm{Ph}+\mathrm{CP}$ CML had progressed to AP/BP on treatment. After a median follow-up of 30.4 months (range 0.7-44.6), 1- and 2-year Kaplan-Meier OS rates, respectively, were $98.0 \%$ and 96.0\%, for patients with $\mathrm{Ph}+\mathrm{CP}$ CML (second-line: 100 and $97.7 \%$; third-line: 96.7 and $95.0 \%$; fourth-line: 97.9 and 95.4\%; Supplementary Fig. S2A). The respective rates were 97.5 and $94.9 \%$ in TKI-resistant and 98.6 and $97.2 \%$ in TKIintolerant patients (Supplementary Fig. S2B). After a median follow-up of 20.6 months (range 1.6-32.3) and 26.5 months (3.5-41.4) for patients with $\mathrm{Ph}+\mathrm{AP} \mathrm{CML}$ and $\mathrm{Ph}-\mathrm{CML}$, respectively, OS rates $(95 \% \mathrm{CI})$ at both 1 year and 2 years were $100 \%$ (100-100\%) and 66.7\% (5.4-94.5\%).

\section{Safety}

In the overall patient population $(N=163), 99.4 \%$ of patients had $\geq 1$ any grade TEAE and $73.6 \%$ of patients had $\geq 1$ grade 3/4 TEAE. Treatment-emergent serious AEs were reported in $35.6 \%$ of patients. TEAEs led to dose reduction and temporary discontinuation in $77.3 \%$ and $75.5 \%$ of patients, respectively, and $42(25.8 \%)$ discontinued treatment due to AEs. The most common AEs leading to discontinuation ( $\geq 2 \%$ of patients) were increased alanine aminotransferase $(4.9 \%)$ and increased aspartate aminotransferase $(2.5 \%)$. In TKI-resistant and TKI-intolerant patients, respectively, rates of any grade TEAEs were $100 \%$ and $98.6 \%$, and rates of grade $3 / 4$ TEAEs were $69.9 \%$ and $79.5 \%$. The rate of dose reductions due to TEAEs was $73.5 \%$ in TKI-resistant patients and $84.9 \%$ in TKI-intolerant patients; respective rate of temporary discontinuations due to TEAEs was $68.7 \%$ and $84.9 \%$. Overall, $21.7 \%$ and $28.8 \%$ of TKI-resistant and TKI-intolerant patients, respectively, discontinued treatment due to AEs. There were no relevant differences in the overall frequency of TEAEs, grade 3/4 TEAEs, or dose reductions/temporary discontinuations due to TEAEs across lines of treatment.

The most common TEAEs $(>30 \%)$ in the overall patient population were diarrhea $(87.7 \%)$, nausea $(39.9 \%)$, and vomiting $(32.5 \%)$ (Table 4$)$. However, only two (1.2\%), three $(1.8 \%)$, and two $(1.2 \%)$ patients discontinued due to diarrhea, nausea, and vomiting, respectively. Median (range) time to first TEAE of diarrhea was 2.0 (1-304) days, and the median (range) duration of diarrhea event (any grade) was $8.0(1-715)$ days. Grade 3/4 TEAEs occurring in $>5 \%$ of patients were diarrhea $(16.0 \%)$, increased alanine aminotransferase (14.1\%), thrombocytopenia (8.0\%), increased lipase (6.7\%), and pleural effusion (6.1\%). TEAEs of special interest included cardiac (14.7\%), vascular $(11.7 \%)$, effusion $(18.4 \%)$, metabolic $(8.0 \%)$, and gastrointestinal (91.4\%; Table 5).
Table 4 Summary of TEAEs (all grade TEAEs reported in $\geq 10 \%$ of patients).

\begin{tabular}{|c|c|c|}
\hline \multirow[t]{2}{*}{$n(\%)$} & \multicolumn{2}{|c|}{ Total $(N=163)$} \\
\hline & All grades & Grades $3 / 4$ \\
\hline Any TEAE & $162(99.4)$ & $120(73.6)$ \\
\hline Diarrhea & $143(87.7)$ & $26(16.0)$ \\
\hline Nausea & $65(39.9)$ & $4(2.5)$ \\
\hline Vomiting & $53(32.5)$ & $6(3.7)$ \\
\hline Abdominal pain & $46(28.2)$ & $7(4.3)$ \\
\hline Headache & $45(27.6)$ & $1(0.6)$ \\
\hline ALT increased & $42(25.8)$ & $23(14.1)$ \\
\hline Fatigue & 39 (23.9) & $2(1.2)$ \\
\hline Abdominal pain upper & $36(22.1)$ & $2(1.2)$ \\
\hline Dyspnea & $35(21.5)$ & $5(3.1)$ \\
\hline Asthenia & $33(20.2)$ & $4(2.5)$ \\
\hline AST increased & $32(19.6)$ & $7(4.3)$ \\
\hline Cough & $30(18.4)$ & $1(0.6)$ \\
\hline Pyrexia & $29(17.8)$ & $5(3.1)$ \\
\hline Constipation & $28(17.2)$ & $2(1.2)$ \\
\hline Arthralgia & $28(17.2)$ & $1(0.6)$ \\
\hline Pleural effusion & $27(16.6)$ & $10(6.1)$ \\
\hline Back pain & $27(16.6)$ & $4(2.5)$ \\
\hline Anemia & $25(15.3)$ & $7(4.3)$ \\
\hline Rash & $25(15.3)$ & $7(4.3)$ \\
\hline Dizziness & $25(15.3)$ & 0 \\
\hline Blood creatinine increased & $24(14.7)$ & 0 \\
\hline Nasopharyngitis & $24(14.7)$ & 0 \\
\hline Lipase increased & $23(14.1)$ & $11(6.7)$ \\
\hline Myalgia & $22(13.5)$ & $2(1.2)$ \\
\hline Decreased appetite & $22(13.5)$ & $1(0.6)$ \\
\hline Edema peripheral & $22(13.5)$ & $1(0.6)$ \\
\hline Thrombocytopenia & $18(11.0)$ & $13(8.0)$ \\
\hline Pain in extremity & $17(10.4)$ & $2(1.2)$ \\
\hline Pruritus & $17(10.4)$ & $2(1.2)$ \\
\hline
\end{tabular}

Full analysis set. Classification of adverse events is based on the Medical Dictionary for Regulatory Activities (v21.1).

$A L T$ alanine aminotransferase, $A S T$ aspartate aminotransferase, $C M L$ chronic myeloid leukemia, TEAE treatment-emergent adverse event.

There were 12 deaths, seven of which occurred within 28 days of last dose (six due to AEs not related to bosutinib and one due to CML, as determined by the investigator) and five deaths occurred beyond 28 days of last dose (four due to AEs not related to bosutinib and one due to an unknown cause, as determined by the investigator). AEs resulting in death were: acute kidney injury, respiratory insufficiency due to aspiration, cerebral tumor, chronic briden-ileus, hemorrhagic shock, lymphoma, metastatic lung cancer, multiorgan failure, prostate adenocarcinoma, and sepsis. 
Table 5 TEAEs of special interest.

\begin{tabular}{|c|c|}
\hline$n(\%)$ & Total $(N=163)$ \\
\hline \multicolumn{2}{|l|}{ Cardiac TEAEs } \\
\hline Any TEAE & $24(14.7)$ \\
\hline Cardiac disorders & $23(14.1)$ \\
\hline Cardiac failure & $6(3.7)$ \\
\hline Atrial fibrillation & $5(3.1)$ \\
\hline Tachycardia & $3(1.8)$ \\
\hline Arrhythmia & $2(1.2)$ \\
\hline Bradycardia & $2(1.2)$ \\
\hline Cardiac failure congestive & $2(1.2)$ \\
\hline Atrial flutter & $1(0.6)$ \\
\hline Atrioventricular block complete & $1(0.6)$ \\
\hline Bundle branch block right & $1(0.6)$ \\
\hline Cardiac failure acute & $1(0.6)$ \\
\hline Cardiac flutter & $1(0.6)$ \\
\hline Cardiogenic shock & $1(0.6)$ \\
\hline Extrasystoles & $1(0.6)$ \\
\hline Sinus bradycardia & $1(0.6)$ \\
\hline Investigations & $1(0.6)$ \\
\hline $\begin{array}{l}\text { Electrocardiogram QT interval } \\
\text { prolonged }\end{array}$ & $1(0.6)$ \\
\hline \multicolumn{2}{|l|}{ Vascular TEAEs } \\
\hline Any TEAE & $19(11.7)$ \\
\hline Cardiovascular & $5(3.1)$ \\
\hline Angina pectoris & $2(1.2)$ \\
\hline Angina unstable & $1(0.6)$ \\
\hline Coronary artery occlusion & $1(0.6)$ \\
\hline Myocardial ischemia & $1(0.6)$ \\
\hline Cerebrovascular & $5(3.1)$ \\
\hline Cerebrovascular accident & $2(1.2)$ \\
\hline Transient ischemic attack & $2(1.2)$ \\
\hline Carotid artery stenosis & $1(0.6)$ \\
\hline Peripheral vascular & $10(6.1)$ \\
\hline Peripheral arterial occlusive disease & $3(1.8)$ \\
\hline Peripheral ischemia & $2(1.2)$ \\
\hline Aortic stenosis & $1(0.6)$ \\
\hline Arterial rupture & $1(0.6)$ \\
\hline Intermittent claudication & $1(0.6)$ \\
\hline Peripheral coldness & $1(0.6)$ \\
\hline Vascular pain & $1(0.6)$ \\
\hline \multicolumn{2}{|l|}{ Effusion TEAEs } \\
\hline Any TEAE & $30(18.4)$ \\
\hline Pleural effusion & $27(16.6)$ \\
\hline Pericardial effusion & $8(4.9)$ \\
\hline \multicolumn{2}{|l|}{ Metabolic TEAEs } \\
\hline Any TEAE & $13(8.0)$ \\
\hline Hyperglycemia & $5(3.1)$ \\
\hline Diabetes mellitus & $4(2.5)$ \\
\hline
\end{tabular}

Table 5 (continued)

\begin{tabular}{lc}
\hline$n(\%)$ & Total $(N=163)$ \\
\hline Hypercholesterolemia & $3(1.8)$ \\
Hypertriglyceridemia & $3(1.8)$ \\
Hyperlipidemia & $1(0.6)$ \\
Gastrointestinal TEAEs & \\
Any TEAE & $149(91.4)$ \\
Diarrhea & $143(87.7)$ \\
Abdominal pain & $67(41.1)$ \\
Nausea & $65(39.9)$ \\
Vomiting & $53(32.5)$ \\
Constipation & $28(17.2)$ \\
\hline
\end{tabular}

Full analysis set. Classification of adverse events is based on the Medical Dictionary for Regulatory Activities (v21.1). See Supp. Methods for adverse events of special interest cluster definitions.

Totals for the number of patients at a higher level are not necessarily the sum of those at the lower levels since a patient may report two or more different TEAEs within the higher level category.

TEAE treatment-emergent adverse events.

\section{PROs}

At baseline, total FACT-Leu scores were similar $(<5 \%$ difference) between the second- and third-line cohorts; slightly lower scores were reported in the fourth-line cohort at baseline (Fig. 3 and Supplementary Table S2). Total FACT-Leu scores were maintained from baseline in all cohorts following 12 months of bosutinib treatment (Fig. 3); additionally, at month 12 , no mean change in any individual FACT-Leu domain score from baseline met the MID, indicating preservation of health-related QoL (HRQoL) (Supplementary Fig. S3; Fig. 3). Within these MIDs, FACT-Leu scores increased slightly from baseline to month 12 in the second-line cohort and (except for emotional wellbeing) decreased slightly in the third-line cohort; positive versus negative changes were less consistent in the fourthline cohort. The effect of MR on HRQoL was variable. For patients who achieved $\mathrm{MR}^{5}$, the leukemia-specific domain showed the greatest improvement, with a large effect size, followed by the emotional well-being domain and TOI FACT-Leu, with medium effect sizes; the social well-being domain was the only domain to demonstrate a beyondtrivial reduction in HRQoL, with a medium effect size (Supplementary Fig. S4).

\section{Discussion}

Overall, data from the phase 4 BYOND study confirm the efficacy findings from the phase $1 / 2$ study of bosutinib in the second-, third- and fourth-line settings [13, 16-20]. High rates of cytogenetic and molecular responses were observed across patients with $\mathrm{Ph}+\mathrm{CP}$ CML treated with bosutinib, 


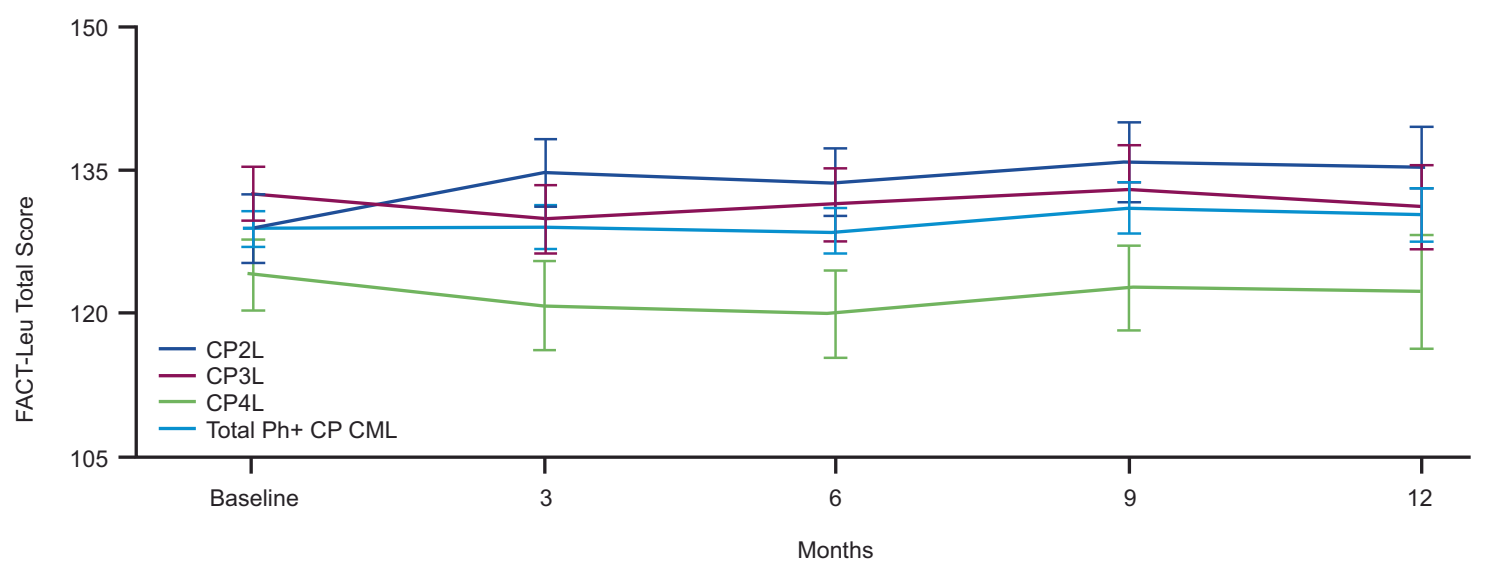

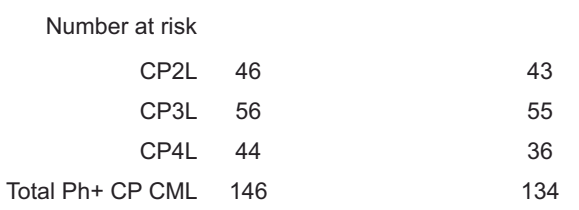

Fig. 3 Observed mean (SE) FACT-Leu values over 12 months of bosutinib treatment. $C M L$ chronic myeloid leukemia, $C P$ chronic phase, $C P 2 L$ second-line, $C P 3 L$ third-line, $C P 4 L$ fourth-line, $F A C T$ -

including a large proportion of patients who achieved deep MR. The majority of patients achieved deeper responses relative to baseline with bosutinib, even though most patients entered the study with at least MCyR from prior treatment. These high response rates were seen in TKI-resistant and TKI-intolerant patients and across treatment lines. Although patients with a more resistant phenotype showed lower response rates compared with TKI-intolerant patients, responses were also seen in patients with resistance to imatinib or the 2nd-generation TKIs dasatinib and nilotinib.

Data in patients with CML resistant/intolerant to prior TKIs were also reported in studies of nilotinib, dasatinib, and ponatinib [11, 14, 21]. In a phase 2 study of second-line nilotinib $400 \mathrm{mg}$ twice daily in imatinib-resistant/intolerant patients $(N=321)$, MCyR, CCyR, and MMR rates at any time on treatment were $59 \%, 44 \%$, and $28 \%$, respectively, after a minimum follow-up of 24 months [21]. In a phase 3 study of second-line dasatinib (multiple doses) in imatinib-resistant/intolerant patients $(N=670)$, MCyR, CCyR and MMR rates by 24 months were $61-63 \%, 50-54 \%$, and $37-38 \%$, respectively [11]. In the present study, second-line bosutinib yielded MCyR, CCyR, and MMR rates (both by 24 months and at any time) of $80.0 \%, 81.3 \%$, and $76.0 \%$, respectively, in patients without the respective baseline response. For bosutinib, achieved rates are used for the purpose of comparisons with the nilotinib and dasatinib studies due to the higher proportion of patients with baseline MCyR enrolled in BYOND: $77.8 \%$ versus $11 \%$ and 14-20\% for nilotinib and dasatinib, respectively $[11,21,22]$. In the present study, response rates were higher in patients treated with fewer previous TKIs; however, response was also seen in heavily pretreated patients: $47.1 \%$ and $38.5 \%$ of patients (without the respective baseline response) treated with bosutinib fourth-line therapy achieved CCyR and MMR, respectively, by 1 year. These data are comparable to those reported in a phase 2 study of ponatinib $45 \mathrm{mg}$ QD in heavily pretreated patients with $\mathrm{CP}$ CML without the T315I mutation $(N=203)$; after a median follow-up of 15 months, MCyR, CCyR, and MMR rates by 12 months were $51 \%, 40 \%$, and $27 \%$, respectively [14]. In summary, the current data for bosutinib from BYOND, with a median follow-up of 30.4 months, showed comparable cytogenetic and molecular response rates to those reported with nilotinib, dasatinib, or ponatinib treatment.

Overall, AEs with bosutinib were manageable. The reported AEs were consistent with the known safety profile of bosutinib and no new safety issues were identified [6, 17-20, 23-27]. Patients intolerant to previous therapies had a slightly higher incidence of grade 3/4 TEAEs and required more frequent dose adjustments to manage AEs than TKI-resistant patients. Nevertheless, most patients intolerant to previous TKIs, including patients intolerant to all prior TKIs, were able to remain on treatment with bosutinib (median treatment duration, 25.3 months). The overall discontinuation rate due to AEs was consistent with the previous phase $1 / 2$ study, despite approximately half of patients being intolerant to all prior TKI therapy, which indicates that, in general, AEs were manageable with dose reductions and temporary discontinuations. Despite a high incidence of diarrhea, which is usually transient and often improves with dietary changes and the administration of supportive care, bosutinib discontinuation due to this $\mathrm{AE}$ 
was low [28]. In patients who have an increase in transaminases, it is advisable to avoid other hepatotoxic drugs and excess alcohol consumption, and monitor liver enzymes more frequently; dose modifications and/or discontinuation may be required in more severe cases [29].

As with imatinib, patients treated with dasatinib or nilotinib may eventually develop resistance to treatment. In addition, some patients may be unable to continue treatment with dasatinib, nilotinib, or ponatinib due to intolerance, or the safety profiles of these agents may preclude their use in patients with certain comorbidities. Safety comparisons across TKI studies are limited; however, the varying "off target" effects of bosutinib, nilotinib, dasatinib, and ponatinib are reflected in the safety of these agents, with each BCR-ABL1 TKI showing a distinct toxicity profile.

Vascular AEs have been described mainly with nilotinib and ponatinib. Metabolic AEs, potentially contributing to vascular toxicity, are also frequently reported with nilotinib $[14,21,30]$. The European LeukemiaNet (ELN) recommendations, therefore, state that nilotinib is contraindicated in patients with a history of coronary heart disease, cerebrovascular accidents, or peripheral arterio-occlusive disease and that previous or concomitant arteriovascular disease is a contraindication to ponatinib in second- or third-line treatment. Pulmonary toxicities, such as pleural effusion and more rarely pulmonary arterial hypertension, have been primarily associated with dasatinib treatment [11, 31-33], and the ELN panel recommended to avoid the use of dasatinib in patients with respiratory failure and previous or concomitant pleuro-pulmonary or pericardial disease. While the incidence of these specific AEs with bosutinib in BYOND was higher than previously reported $[13,16,34,35]$, the heavily pretreated nature of the patients might have contributed to this. ELN recommendations state that no relevant comorbidities or contraindications have been identified for bosutinib [15], and bosutinib is a treatment option for patients with pulmonary or cardiovascular comorbidities, diabetes mellitus, or hyperglycemia due to the lower risk of these types of events [36]. Therefore, bosutinib is an appropriate treatment option for patients resistant or intolerant to prior TKIs, including in patients who have previously received treatment with a 2nd-generation TKI and in those who present with multiple comorbidities.

HRQoL was maintained from baseline in patients with CP CML following 12 months of bosutinib treatment. Changes from baseline in patient-reported outcomes measures at month 12 were comparable to those observed in previously treated patients in the initial phase $1 / 2$ study of bosutinib, wherein long-term efficacy and HRQoL stability were reported [19, 37, 38]. In addition, FACT-G scores in the current study were consistent with those previously reported for bosutinib in newly diagnosed patients with CML, in the general population, as well as in patients with various cancers [39-43]. Maintenance of HRQoL is important for patients with $\mathrm{CP}$ CML who potentially will receive lifelong TKI treatment, and PRO results from this phase 4 study suggest bosutinib is a treatment option with manageable AEs, providing further support for its use in patients with CP CML resistant/intolerant to prior TKIs. The impact of clinical improvement on different dimensions of HRQoL was variable; for the majority of domains, a deeper MR was associated with better HRQoL.

In summary, high rates of cytogenetic and molecular responses, including a large proportion of patients who achieved $\mathrm{MR}^{4}$ and $\mathrm{MR}^{4.5}$, were observed with bosutinib treatment. AEs that occurred with bosutinib were manageable [28, 29], further evidenced by maintenance of HRQoL, and the reported AEs were consistent with the known safety profile of bosutinib. The results from this phase 4 study further confirm the use of bosutinib for patients with CML resistant/intolerant to prior TKIs across all treatment lines.

Acknowledgements The study was sponsored by Pfizer Inc. Medical writing support was provided by Anne Marie McGonigal, PhD CMPP, and Gary Dever, PhD CMPP, of Engage Scientific Solutions and was funded by Pfizer Inc. Open access funding provided by Projekt DEAL.

Additional BYOND Study Investigators E. Abruzzese ${ }^{17}$, L. P. Akard ${ }^{18}$, A. Bosi ${ }^{19}$, F. Cervantes ${ }^{20}$, A. Charbonnier ${ }^{21}$, F. Di Raimondo ${ }^{22}$, G. Etienne ${ }^{23}$, V. Garcia Gutierrez ${ }^{24}$, A. P. Guerci-Bresler ${ }^{25}$, H. HjorthHansen $^{26}$, J. M. Karsenti ${ }^{27}$, K. R. Kelly ${ }^{28}$, P. Le Coutre ${ }^{29}$, C. Martinez Chamorro $^{30}$, V. G. Oehler ${ }^{31}$, G. Orti Pascual ${ }^{32}$, A. Petzer ${ }^{33}$, E. Pungolino $^{34}$, G. Rege-Cambrin ${ }^{35}$, F. Rigal-Huguet ${ }^{36}$, G. J. Roboz ${ }^{37}$, P. Rousselot ${ }^{38}$, F. M. Sanchez-Guijo ${ }^{39}$, G. Sanz Santillana ${ }^{40}$, P. Schafhausen ${ }^{41}$, C. Scheid $^{42}$, S. Schmidt ${ }^{43}$, G. Specchia ${ }^{44}$, J. L. Steegmann ${ }^{45}$, L. Stenke ${ }^{46}$

${ }^{17}$ Ospedale S. Eugenio, Rome, Italy; ${ }^{18}$ Indiana Blood and Marrow Transplantation-Clinic, Indianapolis, IN, USA; ${ }^{19}$ SOD Ematologia, Firenze, Italy; ${ }^{20} \mathrm{Hospital}$ Clinic IDIBAPS, Barcelona, Spain; ${ }^{21}$ Centre Regional De Lutte Contre Le Cancer, Marseille, France; ${ }^{22}$ Policlinico Vittorio Emanuele, Catania, Italy; ${ }^{23}$ Institut Bergonie, Bordeaux, France; ${ }^{24}$ Hospital Universitario Ramon y Cajal, Madrid, Spain; ${ }^{25} \mathrm{CHU}$ Brabois, Vandoeuvre-les-Nancy, France; ${ }^{26} \mathrm{St}$ Olav Hospital, Trondheim, Norway; ${ }^{27} \mathrm{CHU}$ Nice-Hopital Archet, Nice, France; ${ }^{28}$ University of Southern California, Norris Comprehensive Cancer Center, Los Angeles, CA, USA; ${ }^{29}$ Charité - Universitätsmedizin Berlin, Berlin, Germany; ${ }^{30}$ Hospital Universitario Quiron de Madrid, Pozuelo de Alarcon, Madrid, Spain; ${ }^{31}$ Seattle Cancer Care Alliance, Seattle, WA, USA; ${ }^{32}$ Vall d'Hebron University Hospital, Barcelona, Spain; ${ }^{33}$ Ordensklinikum Linz Gmbh Barmherzige Schwestern, Linz, Austria; ${ }^{34}$ Ospedale Niguarda Ca Granda, Milano, Italy; ${ }^{35}$ San Luigi Gonzaga SCDU, Orbassano, Italy; ${ }^{36}$ Institut Universitaire du Cancer Toulouse, Toulouse, France; ${ }^{37}$ Weill Cornell Medical College - New York-Presbyterian Hospital, New York, NY, USA; ${ }^{38}$ Centre Hospitalier de Versailles, Hopital Andre Mignot, Le Chesnay, France; ${ }^{39}$ Hospital Clinico Universitario de Salamanca, Salamanca, Spain; ${ }^{40}$ Hospital Universitari i Politecnic La Fe, Valencia, Spain; ${ }^{41}$ Universitätsklinikum HamburgEppendorf, Hamburg, Germany; ${ }^{42}$ Universitätsklinikum Köln, Köln, Germany; ${ }^{43}$ Medizinische Universität Innsbruck, Innsbruck, Austria; ${ }^{44}$ Policlinico Consorziale di Bari, Bari, Italy; ${ }^{45}$ Hospital Universitario de La Princesa, Madrid, Spain; 46Hematologiskt Centrum, Stockholm, Stockholm, Sweden 
Author contributions All authors were involved in the study conception/design, or the acquisition, analysis, or interpretation of data. All authors contributed to the drafting of the manuscript and approved the final version.

\section{Compliance with ethical standards}

Conflict of interest Authors declare the following potential conflicts of interest: AH received honoraria from BMS, Novartis, Pfizer, and Takeda, and received research support from BMS, Incyte, Novartis, and Pfizer. CGP provides consultancy to BMS and received honoraria and research support from Pfizer. CA serves on the advisory board for Archer DX, Jazz Pharma, and Tetraphase Pharma, provides consultancy to Actinium, Agios, Bayer, Cardinal Health, Gerson Lehman Group, Incyte, Jazz Pharma, NKarta, Pfizer, Seattle Genetics, and Tetraphase Pharma, received honoraria from Agios, Cardinal Health, and Jazz Pharma, received research support from Pfizer, and serves on the speakers bureau for Jazz Pharma / provides expert testimony for Dava Oncology. BTG is a consultant for BerGenBio, Novartis, Pfizer, and Sanofi Genzyme, received research support from Pfizer, and has stock ownership in Alden Cancer Therapy AS and KinN Therapeutics AS. THB is a consultant for Janssen, Merck, Novartis, Pfizer, and Takeda, and received research support from Novartis and Pfizer. BDS received honoraria for consulting to Agios, Celgene, Jazz Pharma, Novartis and Pfizer, and received research support from Pfizer. PGC received research support from BMS and Pfizer. UOS received research support from Pfizer. SS received honoraria from BMS, Incyte, Novartis, and Pfizer, and received research support from BMS, Incyte, Novartis, and Pfizer. TE received research support from BMS, Incyte, Novartis, and Pfizer. NBB, AV, EL, ARS and JL are employees of Pfizer. GR received research support from Pfizer and served on the speaker bureau for BMS, Incyte, Novartis, and Pfizer. JW serves on the advisory board for Jazz Pharma and Takeda, received research support from Pfizer and Takeda, and serves on the data monitoring committee for Rafael Pharma. FJG is a consultant to Actuate Therapeutics Inc, provides expert testimony to Novartis, and received research support from Pfizer.

Data Sharing Upon request, and subject to certain criteria, conditions and exceptions (see https://www.pfizer.com/science/clinical-trials/trialdata-and-results for more information), Pfizer will provide access to individual de-identified participant data from Pfizer-sponsored global interventional clinical studies conducted for medicines, vaccines and medical devices (1) for indications that have been approved in the USA and/or Europe or (2) in programs that have been terminated (i.e., development for all indications has been discontinued). Pfizer will also consider requests for the protocol, data dictionary, and statistical analysis plan. Data may be requested from Pfizer trials 24 months after study completion. The de-identified participant data will be made available to researchers whose proposals meet the research criteria and other conditions, and for which an exception does not apply, via a secure portal. To gain access, data requestors must enter into a data access agreement with Pfizer.

Publisher's note Springer Nature remains neutral with regard to jurisdictional claims in published maps and institutional affiliations.

Open Access This article is licensed under a Creative Commons Attribution 4.0 International License, which permits use, sharing, adaptation, distribution and reproduction in any medium or format, as long as you give appropriate credit to the original author(s) and the source, provide a link to the Creative Commons license, and indicate if changes were made. The images or other third party material in this article are included in the article's Creative Commons license, unless indicated otherwise in a credit line to the material. If material is not included in the article's Creative Commons license and your intended use is not permitted by statutory regulation or exceeds the permitted use, you will need to obtain permission directly from the copyright holder. To view a copy of this license, visit http://creativecommons. org/licenses/by/4.0/.

\section{References}

1. National Cancer Institute. Chronic Myelogenous Leukemia Treatment (PDQ ${ }^{\circ}$ ). 2020. https://www.cancer.gov/types/leukemia/ hp/cml-treatment-pdq\#_1

2. O'Brien SG, Deininger MW. Imatinib in patients with newly diagnosed chronic-phase chronic myeloid leukemia. Semin Hematol. 2003;40:26-30.

3. O'Brien SG, Guilhot F, Larson RA, Gathmann I, Baccarani M, Cervantes $\mathrm{F}$, et al. Imatinib compared with interferon and lowdose cytarabine for newly diagnosed chronic-phase chronic myeloid leukemia. N. Engl J Med. 2003;348:994-1004.

4. Kantarjian H, Shah NP, Hochhaus A, Cortes J, Shah S, Ayala M, et al. Dasatinib versus imatinib in newly diagnosed chronic-phase chronic myeloid leukemia. N. Engl J Med. 2010;362:2260-70.

5. Saglio G, Kim DW, Issaragrisil S, le Coutre P, Etienne G, Lobo C, et al. Nilotinib versus imatinib for newly diagnosed chronic myeloid leukemia. N Engl J Med. 2010;362:2251-9.

6. Cortes JE, Gambacorti-Passerini C, Deininger MW, Mauro MJ, Chuah C, Kim DW, et al. Bosutinib versus imatinib for newly diagnosed chronic myeloid leukemia: results from the randomized BFORE trial. J Clin Oncol. 2018;36:231-7.

7. Jabbour E, Kantarjian H. Chronic myeloid leukemia: 2018 update on diagnosis, therapy and monitoring. Am J Hematol. 2018;93:442-59.

8. Jabbour E, Kantarjian H, Cortes J. Use of second- and thirdgeneration tyrosine kinase inhibitors in the treatment of chronic myeloid leukemia: an evolving treatment paradigm. Clin Lymphoma Myeloma Leuk. 2015;15:323-34.

9. García-Gutiérrez V, Hernández-Boluda JC. Tyrosine kinase inhibitors available for chronic myeloid leukemia: efficacy and safety. Front Oncol. 2019;9:603 https://doi.org/10.3389/fonc.2019. 00603. eCollection 2019

10. Hochhaus A, Ernst T, Eigendorff E, La Rosée P. Causes of resistance and treatment choices of second- and third-line treatment in chronic myelogenous leukemia patients. Ann Hematol. 2015;94 Suppl 2:S133-40.

11. Shah NP, Kim DW, Kantarjian H, Rousselot P, Llacer PE, Enrico A, et al. Potent, transient inhibition of BCR-ABL with dasatinib $100 \mathrm{mg}$ daily achieves rapid and durable cytogenetic responses and high transformation-free survival rates in chronic phase chronic myeloid leukemia patients with resistance, suboptimal response or intolerance to imatinib. Haematologica. 2010;95:232-40

12. Kantarjian HM, Giles F, Gattermann N, Bhalla K, Alimena G, Palandri F, et al. Nilotinib (formerly AMN107), a highly selective BCR-ABL tyrosine kinase inhibitor, is effective in patients with Philadelphia chromosome-positive chronic myelogenous leukemia in chronic phase following imatinib resistance and intolerance. Blood. 2007;110:3540-6.

13. Cortes JE, Kantarjian HM, Brümmendorf TH, Kim DW, Turkina AG, Shen ZX, et al. Safety and efficacy of bosutinib (SKI-606) in chronic phase Philadelphia chromosome-positive chronic myeloid leukemia patients with resistance or intolerance to imatinib. Blood. 2011;118:4567-76.

14. Cortes JE, Kim DW, Pinilla-Ibarz J, le Coutre P, Paquette R, Chuah $\mathrm{C}$, et al. A phase 2 trial of ponatinib in Philadelphia chromosome-positive leukemias. N Engl J Med. 2013;369: 1783-96. 
15. Hochhaus A, Baccarani M, Silver RT, Schiffer C, Apperley JF, Cervantes F, et al. European LeukemiaNet 2020 recommendations for treating chronic myeloid leukemia. Leukemia. 2020;34:966-84.

16. Khoury HJ, Cortes JE, Kantarjian HM, Gambacorti-Passerini C, Baccarani M, Kim DW, et al. Bosutinib is active in chronic phase chronic myeloid leukemia after imatinib and dasatinib and/or nilotinib therapy failure. Blood. 2012;119:3403-12.

17. Brümmendorf TH, Cortes JE, Khoury HJ, Kantarjian HM, Kim DW, Schafhausen P, et al. Factors influencing long-term efficacy and tolerability of bosutinib in chronic phase chronic myeloid leukaemia resistant or intolerant to imatinib. Br J Haematol. 2016;172:97-110.

18. Cortes JE, Khoury HJ, Kantarjian HM, Lipton JH, Kim DW, Schafhausen $\mathrm{P}$, et al. Long-term bosutinib for chronic phase chronic myeloid leukemia after failure of imatinib plus dasatinib and/or nilotinib. Am J Hematol. 2016;91:1206-14.

19. Gambacorti-Passerini C, Cortes JE, Lipton JH, Kantarjian HM, Kim D-W, Schafhausen P, et al. Safety and efficacy of second-line bosutinib for chronic phase chronic myeloid leukemia over a fiveyear period: final results of a phase I/II study. Haematologica. 2018;103:1298-307.

20. Gambacorti-Passerini C, Brümmendorf TH, Kim DW, Turkina AG, Masszi T, Assouline S, et al. Bosutinib efficacy and safety in chronic phase chronic myeloid leukemia after imatinib resistance or intolerance: minimum 24-month follow-up. Am J Hematol. 2014;89:732-42.

21. Kantarjian HM, Giles FJ, Bhalla KN, Pinilla-Ibarz J, Larson RA, Gattermann N, et al. Nilotinib is effective in patients with chronic myeloid leukemia in chronic phase after imatinib resistance or intolerance: 24-month follow-up results. Blood. 2011;117:1141-5.

22. Shah NP, Kantarjian HM, Kim DW, Rea D, Dorlhiac-Llacer PE, Milone JH, et al. Intermittent target inhibition with dasatinib 100 mg once daily preserves efficacy and improves tolerability in imatinib-resistant and -intolerant chronic-phase chronic myeloid leukemia. J Clin Oncol. 2008;26:3204-12.

23. Gambacorti-Passerini C, Cortes JE, Lipton JH, Dmoszynska A, Wong RS, Rossiev V, et al. Safety of bosutinib versus imatinib in the phase 3 BELA trial in newly diagnosed chronic phase chronic myeloid leukemia. Am J Hematol. 2014;89:947-53.

24. Cortes JE, Mauro MJ, Deininger MW, Chuah C, Kim DW, Kota $\mathrm{V}$, et al. Bosutinib vs imatinib for newly diagnosed chronic myeloid leukemia in the BFORE trial: 24-month follow-up. J Clin Oncol. 2018;36(15_suppl):7002. (abstract).

25. Cortes JE, Kim DW, Kantarjian HM, Brümmendorf TH, Dyagil I, Griskevicius L, et al. Bosutinib versus imatinib in newly diagnosed chronic-phase chronic myeloid leukemia: results from the BELA trial. J Clin Oncol. 2012;30:3486-92.

26. Brümmendorf TH, Gambacorti-Passerini C, Hochhaus A, Lipton $\mathrm{JH}$, Kota V, Deininger MW, et al. Efficacy and safety following dose reduction of bosutinib or imatinib in patients with newly diagnosed chronic myeloid leukemia: analysis of the phase 3 BFORE trial. Blood. 2018;132:3005. (abstract)

27. Brümmendorf TH, Cortes JE, de Souza CA, Guilhot F, Duvillié L, Pavlov D, et al. Bosutinib versus imatinib in newly diagnosed chronic-phase chronic myeloid leukaemia: results from the 24-month follow-up of the BELA trial. Br J Haematol. 2015;168:69-81.

28. Khoury HJ, Gambacorti-Passerini C, Brümmendorf TH. Practical management of toxicities associated with bosutinib in patients with Philadelphia chromosome-positive chronic myeloid leukemia. Ann Oncol. 2018;29:578-87.
29. Cortes JE, Apperley JF, DeAngelo DJ, Deininger MW, Kota VK, Rousselot $\mathrm{P}$, et al. Management of adverse events associated with bosutinib treatment of chronic-phase chronic myeloid leukemia: expert panel review. J Hematol Oncol. 2018;11:143.

30. Medeiros BC, Possick J, Fradley M. Cardiovascular, pulmonary, and metabolic toxicities complicating tyrosine kinase inhibitor therapy in chronic myeloid leukemia: Strategies for monitoring, detecting, and managing. Blood Rev. 2018;32:289-99.

31. Montani D, Bergot E, Gunther S, Savale L, Bergeron A, Bourdin A, et al. Pulmonary arterial hypertension in patients treated by dasatinib. Circulation. 2012;125:2128-37.

32. Shah NP, Wallis N, Farber HW, Mauro MJ, Wolf RA, Mattei D, et al. Clinical features of pulmonary arterial hypertension in patients receiving dasatinib. Am J Hematol. 2015;90:1060-4.

33. Hughes TP, Laneuville P, Rousselot P, Snyder DS, Rea D, Shah NP, et al. Incidence, outcomes, and risk factors of pleural effusion in patients receiving dasatinib therapy for Philadelphia chromosomepositive leukemia. Haematologica. 2019;104:93-101.

34. Cortes JE, Jean Khoury H, Kantarjian H, Brümmendorf TH, Mauro MJ, Matczak E, et al. Long-term evaluation of cardiac and vascular toxicity in patients with Philadelphia chromosomepositive leukemias treated with bosutinib. Am J Hematol. 2016;91:606-16.

35. Steegmann JL, Baccarani M, Breccia M, Casado LF, GarciaGutierrez V, Hochhaus A, et al. European LeukemiaNet recommendations for the management and avoidance of adverse events of treatment in chronic myeloid leukaemia. Leukemia. 2016;30:1648-71.

36. Gambacorti-Passerini C, le Coutre P, Piazza R. The role of bosutinib in the treatment of chronic myeloid leukemia. Future Oncol. 2020;16:4395-408.

37. Trask PC, Cella D, Besson N, Kelly V, Masszi T, Kim DW. Health-related quality of life of bosutinib (SKI-606) in imatinibresistant or imatinib-intolerant chronic phase chronic myeloid leukemia. Leuk Res. 2012;36:438-42.

38. Whiteley J, Reisman A, Shapiro M, Cortes J, Cella D. Healthrelated quality of life during bosutinib (SKI-606) therapy in patients with advanced chronic myeloid leukemia after imatinib failure. Curr Med Res Opin. 2016;32:1325-34.

39. Cella D, Jensen SE, Webster K, Hongyan D, Lai JS, Rosen S, et al. Measuring health-related quality of life in leukemia: the Functional Assessment of Cancer Therapy-Leukemia (FACTLeu) questionnaire. Value Health. 2012;15:1051-8.

40. Brucker PS, Yost K, Cashy J, Webster K, Cella D. General population and cancer patient norms for the functional assessment of cancer therapy-general (FACT-G). Eval Health Prof. 2005;28:192-211.

41. Pearman T, Yanez B, Peipert J, Wortman K, Beaumont J, Cella D. Ambulatory cancer and US general population reference values and cutoff scores for the functional assessment of cancer therapy. Cancer. 2014;120:2902-9.

42. Cortes JE, Gambacorti-Passerini C, Deininger MW, Mauro MJ, Chuah C, Kim DW, et al. Patient-reported outcomes in the phase 3 BFORE trial of bosutinib versus imatinib for newly diagnosed chronic phase chronic myeloid leukemia. J Cancer Res Clin Oncol. 2019;145:1589-99.

43. Brümmendorf TH, Gambacorti-Passerini C, Bushmakin AG, Cappelleri JC, Viqueira A, Reisman A, et al. Relationship between molecular response and quality of life with bosutinib or imatinib for chronic myeloid leukemia. Ann Hematol. 2020;99:1241-9. 